\title{
Flow Regime Transition and Air Entrapment in Combined Sewer Storage Tunnels
}

\author{
Steven J. Wright, Jose G. Vasconcelos, James W. Lewis \\ and Calvin T. Creech
}

The rapid filling of a stormwater storage tunnel is accompanied by a flow regime transition from free surface to pressurized flow with the presence of a hydraulic bore. Nearly all previous experimental investigations of flow regime transition have involved the study of pipe-filling bores; this seems to be a consequence of the experimental setup implemented as opposed to a necessarily common occurrence in prototype systems. In analyzing transient filling conditions in a large combined sewer overflow storage tunnel proposed for Washington DC, it became clear that the flow regime transition more commonly occurs as a gradual flow regime transition which involves a regular free surface bore followed by a gradually sloping free surface up to the pipe crown. This unsteady process can result in air pockets being trapped and pressurized in the system. As these air pockets reach a ventilation shaft, they can be quickly released upward in an air-water mixture. This phenomenon known as geysering potentially results in the untreated poor quality water returning to the surface. Laboratory experiments were used to observe the formation of pressurized air pockets and geysering events associated with gradual flow regime conditions. Geysers that occur due to the release of these air pockets do not necessarily correspond to high pressures in the system. The consequences of these observations for the requirements of numerical models are discussed. It is also

Wright, S.J., J. Vasconcelos, J. Lewis and C.T. Creech. 2009. "Flow Regime Transition and Air Entrapment in Combined Sewer Storage Tunnels." Journal of Water Management Modeling R235-15. doi: 10.14796/JWMM.R235-15.

(C) CHI 2009 www.chijournal.org ISSN: 2292-6062 (Formerly in Conceptual Modeling of Urban Water Systems. ISBN: 978-0-9808853-2-3) 
shown that the geysering phenomenon can be significantly reduced by altering the geometry of the ventilation shafts.

\subsection{Introduction}

Changes in the regulatory climate for stormwater management have led to extensive modifications to existing combined sewer overflow systems. The objectives of the modifications are to reduce the number and magnitude of overflows to surface water bodies. Generally, the most cost-effective approach to the solution of these problems is to provide temporary storage to capture the peaks of all but the major storm events. Although various retention alternatives have been implemented, a common approach is to construct a below grade storage tunnel connected to the combined sewer system at the previous overflow points from which the combined sewage is diverted into storage once the capacity of the sewer system is exceeded. Under conditions of more significant rainfall, the capacity of the storage tunnel itself may be exceeded and the additional inflow is discharged to the environment, usually with some low level of treatment such as solids deposition and disinfection.

The filling of the storage tunnel system occurs in an uncontrolled fashion, depending on the rainfall distribution patterns, the characteristics of the sewer drainage network, and the hydrological features of the watershed. Historically, a number of storage tunnel systems have experienced flow problems associated with the filling process. Several separate phenomena have been identified as sources for concern; these include surges in vertical shafts, large transient pressure spikes, and the occurrence of geysers. Guo and Song (1990) discuss the phenomenon of geysering but proceed to the analysis of pressure surges. Zhou, et al. (2002) suggest that high pressure transients may be produced by trapped air within the system, a process that is ignored by Guo and Song. Laboratory investigations of the phenomena involved in the filling of nearly horizontal pipes, suggests that all of these phenomena can be interlinked and related to the process by which the tunnel undergoes a transition between the free surface flow state in the early stages of the filling process to a completely pressurized state as the storage capacity of the tunnel is exceeded. Therefore it is critical to be able to represent the flow regime transition accurately in numerical models that are developed to analyze the transient conditions associated with the rapid filling of combined sewer or stormwater systems. Discussions of many important issues associated with flow regime transition are not provided in previous literature, suggesting that critical conditions for geyser formation are not clearly understood. The objectives of this chapter are to relate some experimental 
observations from studies performed by the authors, to discuss the requirements for numerical models that must replicate these phenomena, and to indicate the capability of model formulations adopted by the authors to meet these needs. The results of initial efforts to mitigate geyser formation are also presented.

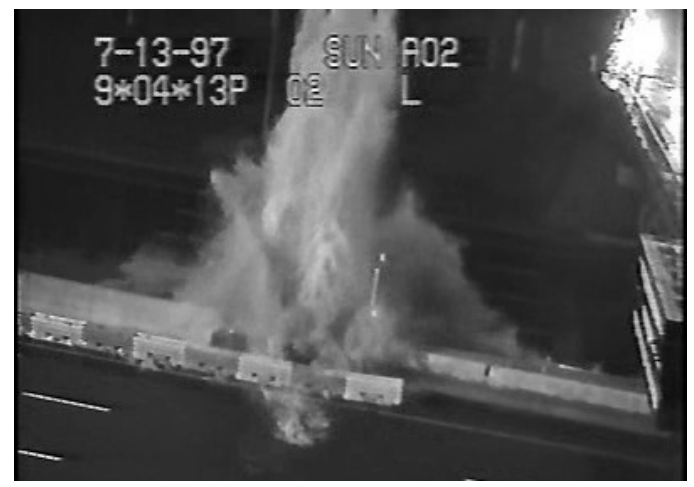

Figure 15.1 Image from a video record of a geyser event in a stormwater tunnel in Minneapolis, Minnesota.

The phenomenon of geysering has been discussed for many years. An image of a geyser event captured on video is shown in Figure 15.1. Using nearby objects for scale, it appears that the discharge reaches on the order of $20-30 \mathrm{~m}$ above the ground surface. From the image (and even more so from the video from which it was extracted), it appears that the phenomenon results from the discharge of a mixture of air and water through the large diameter manhole. Geysering was observed in the early operation of the Chicago Tunnel and Reservoir Project and solutions to this problem drove much of the research performed at the University of Minnesota, resulting in numerical model development such as discussed by Cardle and Song (1988). A photograph of a geyser event is included in Guo and Song (1990) and is discussed in the introduction to that paper. A related paper by Guo (1989) includes geysering in the title as well. However the analysis presented in both papers makes no mention of air involvement and analyzes the water flow as a surge problem. This is an important consideration with respect to system design, since a water jet reaching $20 \mathrm{~m}$ into the air implies a significant internal pressure within the tunnel whereas no such conclusion is possible if the event consists of the discharge of a mixture of air and water. Wright, et al. (2007) discussed the hypothesized events that developed during a geysering event and some of the factors that control the strength of the geyser. The word hypothesized is 
emphasized since the description is based on observations in small scale laboratory experiments as well as theoretical understanding of two-phase flow processes. As limited as these previous results are, they are apparently the only such description available in the literature. This chapter supplements those previous experiments with some additional observations to reinforce the original description and to provide the results of some preliminary investigations into effective ways to mitigate geyser formation.

\subsection{Background}

\subsubsection{Mechanisms of Geyser Formation}

Under certain conditions, the flow regime transition may occur in ways that trap significant volumes of air at the pipe crown. Vasconcelos and Wright (2006) suggest a variety of ways that this air entrapment can occur, depending on the tunnel geometry and the mode of filling. Subsequent experiments have indicated additional ways that air entrapment occurs. In particular, there is one that is believed to be ubiquitous in rapidly filling stormwater systems and will be discussed in more detail below. Once the trapped air pocket is formed, it is transported along the pipe crown due to gravitational (buoyancy) effects in a sloping tunnel, hydrodynamic forces due to the flowing water, or some combination of the two. Since the tunnel is in a pressurized state, both the air and water in the tunnel are above atmospheric pressure. Once the air pocket reaches a vertical shaft in the tunnel (this could be an access shaft or a ventilation shaft) it starts to rise up the shaft due to its buoyancy, intruding on the water that stands in the shaft due to being greater than atmospheric pressure within the tunnel. The rising air forces the water to flow both upwards as well as downwards in a type of film flow around the circumference of the rising air column. If sufficient water can leak back down around the air column, geyser formation may be limited. On the other hand, if the escape of water is limited, the rising water is literally propelled upwards by the escaping air. Vasconcelos (2005) reports on experiments that demonstrate this process and indicates that one of the key variables controlling this process is the shaft diameter relative to the conduit diameter. In particular, a small diameter vertical shaft will result in strong upward accelerations in the water column. The remaining step in the process, which is largely hypothesized, but supported by experiments performed in other contexts (e.g. Guedes et al., 2000) is that the exchange 
flow created by the rising air column and the down-flowing water film results in a condition referred to in the two-phase flow literature as flooding instability and is manifest by waves forming at the air/water interface and the subsequent entrainment of water into the rising air, creating the geyser conditions indicated in Figure 15.1. At a small laboratory scale, it is not possible to create velocity differences sufficiently large to initiate flooding instability, but velocity heads sufficient to eject an air/water mixture $20 \mathrm{~m}$ into the air are clearly sufficient to trigger this condition.

\subsubsection{Types of Flow Regime Transition}

When a nearly horizontal conduit is filled sufficiently rapidly, hydraulic bores, or moving hydraulic jumps can be generated. These hydraulic bores may be one of two types; an ordinary bore with free surface flow on both sides of the bore or what is referred to as a pipe-filling bore in which the bore represents a transition between free surface and pressurized flow. Figure 15.2 presents a depiction of the pipe-filling bore which is one type of flow regime transition. In the case of a free surface bore, there may be a gradual transition to a pressurized condition potentially well behind the bore although the distance involved will depend on the frictional resistance, the filling conditions, and the geometry of the pipeline. This situation is referred to as a gradual flow regime transition and is depicted schematically in Figure 15.3. Previous experimental investigations have mainly created conditions that result in the pipe-filling bore flow regime transition, although a notable exception is the study by Trajkovic, et al. (1999) in which the most common experimental observation was of a gradual flow regime transition.

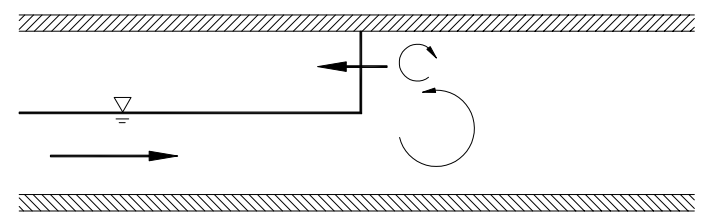

Figure 15.2 Schematic of a pipe-filling bore.

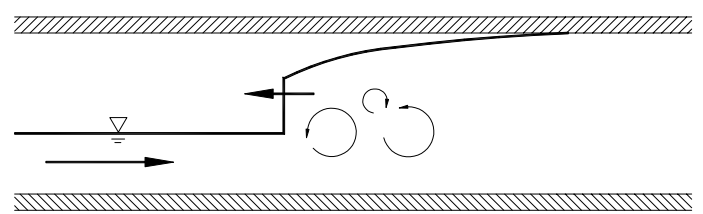

Figure 15.3 Schematic of a free surface bore followed by a gradual flow regime transition. 


\subsubsection{Air Entrapment Mechanisms}

Storage tunnels are often constructed on a small slope to facilitate dewatering after storm events. A common scenario during filling involves the entering water flowing down the slope with the tunnel undergoing the flow regime transition at or near the portion of the tunnel with the lowest elevation. This flow regime transition then propagates to the higher elevation end of the system. Both surges and geysers are possible outcomes associated with the propagation of the filling front, especially following the reflection of the filling front at the upstream end of the tunnel system. Because there are many different geometrical conditions associated with systems that have been constructed to date, it is stressed that this description is only a generalization and may not apply to all systems or to all filling events. Given this sequence of events, it appears that an important way for air to become trapped in a tunnel system is for a gradual flow regime transition to propagate until it arrives at a location where it is partially or completely reflected, resulting in a pressurized condition at the reflection location. Depending on specifics of the geometry and the filling process, the potential exists to trap the large volume of air lying above the water surface between the location of the bore and the actual flow regime transition. Proper placement of adequate ventilation is critical to eliminating the air from the tunnel without the occurrence of geysers. Discussion of this situation appears to be absent from the previous literature on transients in rapidly filling tunnel systems.

The first two authors were responsible for a transient modeling effort on a CSO storage tunnel proposed by the Washington DC Water and Sewer Authority. In that effort, the inflow hydrographs for the tunnel project were generated by modeling the sewer system flow for a series of observed or design rainfall events. Overflows from the sewer system were used to define inflows into the tunnel project. In the majority of simulations performed, the resulting flow regime transitions were predicted to be of the gradual type. Although gradual flow regime transitions were observed in the laboratory studies of Vasconcelos (2005), most of the observed transitions were through pipe-filling bores. It appears that the differences between the laboratory observations and the prototype system predictions are primarily due to two factors: (i) the relatively shorter conduit length in the laboratory model prevents gradual flow regime transition before reflections from one of the two pipe ends creates a pipe-filling bore, and (ii) the laboratory model was tested by creating an essentially instantaneous inflow rather than the more gradual filling hydrographs created by the interaction of the 
rainfall/runoff process with the surface sewer system. Consequently, it is believed that many prototype systems will more typically experience gradual flow regime transitions as compared to pipe-filling bores.

\subsubsection{Required Numerical Model Capability}

Numerical models used for transient analyses of rapidly filling sewer systems must be capable of resolving pipe-filling bores and gradual flow regime transitions. There are two general classes of numerical models that can be implemented to simulate rapid filling problems involving hydraulic bores. Shock fitting methods involve tracking the flow regime transition through the pipeline since different sets of governing equations are required to simulate free surface and pressurized flow conditions. In principle, this could be implemented for both pipe filling bores and gradual flow regime transitions, although the common application is only for pipe filling bores. A typical procedure is that of Cardle and Song (1988) in which different implementations of the Method of Characteristics are applied for the free surface and pressurized portions of the flow and the bore speed is computed by applying discrete continuity and momentum equations across the bore. In this application, an additional variable that is solved for is the bore speed so that the location of the bore can be updated for each computational time step. However, this method or related ones relies on the presumption that the flow regime transition from free surface to pressurized flows occurs as a pipe filling bore. Shock fitting methods of this type are therefore less appropriate for tracking gradual flow regime transitions. In addition, the method of characteristics such as applied by Cardle and Song cannot accurately simulate a free surface bore which poses potential problems in simulating the conditions following the bore reflection at a pipe transition. It is noted that there are other solution methods available for more accurate simulation of free surface bores, including approximate Riemann solvers as described below. A more recent model by Politano, et al. (2007), while still based on the method of characteristics solution approach, includes a provision for explicitly accounting for the gradual flow regime transition interface condition, although it is not clear exactly how the model distinguishes between the two different types of flow regime transition.

The second class of numerical model is referred to as a shock capturing model. A single set of equations is applied to both the free surface and pressurized portions of the flow and a numerical scheme that is capable of numerically resolving the bore is required. The approach uses the St. Venant equations for free surface flow to solve for the pressurized portion of the 
flow regime by appropriate transformation of the equations. This type of scheme has the potential to accurately simulate both types of bore. The Preissman slot scheme has been traditionally implemented in shock capturing schemes as typified by the model of Capart, et al. (1997). More recently, Vasconcelos et al. (2006) proposed the two-component pressure approach (TPA) as an alternative method; this method utilizes the concept of elastic pipe walls to provide the storage term necessary to simulate transient pressurized flow. It provides some computational advantages over the Preissman slot methods, but effectively is a similar approach to the solution of mixed flow conditions.

\subsection{Experimental Investigation}

The experimental investigation was conducted to achieve multiple objectives. These included:

- creation of both types of flow regime transition with the same experimental setup;

- demonstration that water could be forced to large elevations (considerably in excess of hydrostatic pressures) within a vertical standpipe connected to the filling pipeline due to the effects of entrapped air; and

- investigation of methods to release the air without creating large water lifts.

The bores were formed by suddenly introducing flow at the upstream end of an initially empty pipe. An actual system would experience inflow hydrographs at a number of discrete locations. However, the essential behavior of a typical tunnel filling scenario (flow regime transition initiating at the lower elevation end of the system) could be reproduced with the simpler experimental configuration and no attempts were made to reproduce complex filling scenarios that could develop in more complicated systems. The reflection of the filling front at the closed downstream end of the pipe created a bore that subsequently propagated back towards the filling end. Depending on the inflow rate applied at the filling location, the resulting bore could be either of the free surface or pipe-filling type. The laboratory setup for this experiment is indicated in Figure 15.4. The system consists of a $0.095-\mathrm{m}$ diameter clear acrylic pipe, with a total length of $14.14 \mathrm{~m}$ placed initially level inside an adjustable slope flume. Once the system was constructed and leveled, a slope of $0.391 \%$ was obtained by adjusting the 
flume slope. The pipe was capped at the downstream end and a vertical inlet pipe was constructed at the upstream end. This inlet standpipe was connected to a directional valve that could allow flow to either enter the pipe system or it could discharge flow to waste. Rapid switching of the valve allowed a sudden and nearly constant inflow rate. The inflow dropped through a vertical pipe of the same diameter $(0.095 \mathrm{~m})$ approximately one meter in height under the influence of gravity before being diverted through a pipe elbow into the nearly horizontal pipe. The inlet condition into the pipe was poor, creating waves on the interface of the free surface flow in the pipe and creating some air entrainment. Flow was controlled upstream of the directional valve and metered to provide a range of flow discharges. The main objective in this set of experiments was to determine the influence of the discharge on the nature of the resulting bore. Four discharges were used to investigate this behavior; namely $0.84 \mathrm{~L} / \mathrm{s}, 1.39 \mathrm{~L} / \mathrm{s}, 1.91 \mathrm{~L} / \mathrm{s}$, and $2.36 \mathrm{~L} / \mathrm{s}$. The discharge was determined using a calibrated Venturi meter and was essentially constant over the duration of the experiment. Table 15.1 summarizes the experimental conditions investigated for this set of experiments

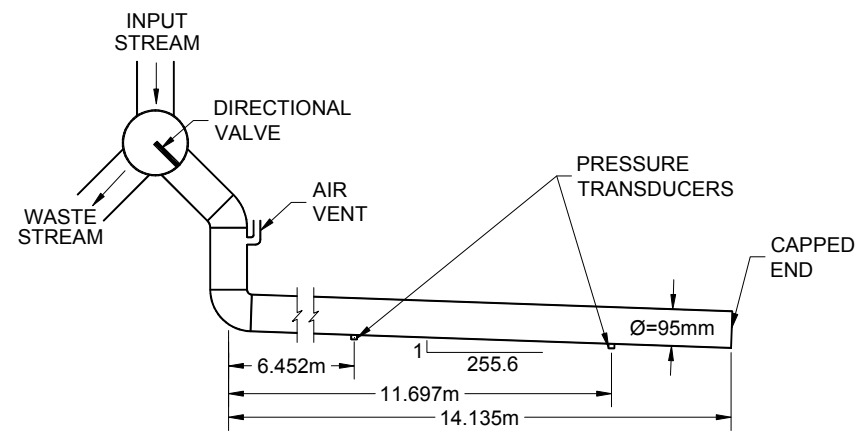

Figure 15.4 Experimental setup.

Table 15.1 Flow regime transition experiments.

\begin{tabular}{cccc}
\hline Label & Flow (L/s) & Slope (\%) & Init. Water Level \\
\hline 1 & 2.36 & 0.391 & 0 \\
2 & 1.91 & 0.391 & 0 \\
3 & 1.39 & 0.391 & 0 \\
4 & 0.84 & 0.391 & 0 \\
\hline
\end{tabular}


Additional experiments to meet the remaining research objectives were made with minor modifications to the apparatus described above. A $0.038 \mathrm{~m}$-diameter vertical standpipe was connected to the pipe at approximately the midpoint. The ratio of the standpipe diameter to pipe diameter of 0.4 was intermediate in the range of values studied by Vasconcelos (2005). This choice was made to prevent the extreme geysering conditions Vasconcelos observed at small diameter ratios but still small enough to expect a significant effect. The main pipe was set in a horizontal condition and many experiments were performed with an initial level of stagnant water within the pipeline. The flow was incremented in two steps in these experiments. The flow was initially switched on to create a free surface bore that propagated to the opposite end of the pipeline and created a gradual flow regime transition following reflection at the closed end of the pipe. As this bore was returning to the fill location, the inflow was increased to create a second bore from the upstream end that collided with the first bore in the vicinity of the ventilation riser. Due to the method for initiating the second flow rate, the resulting bore was not sharp but still served to meet the experimental objectives. Table 15.2 summarizes the experiments performed in this set of experiments.

Table 15.2 Bore collision experiments.

\begin{tabular}{ccccc}
\hline Label & $1^{\text {st }}$ Flow $(\mathrm{L} / \mathrm{s})$ & $2^{\text {nd }}$ Flow (L/s) & Slope (\%) & $\begin{array}{c}\text { Init. water level } \\
\text { (\% Diameter) }\end{array}$ \\
\hline S1 & 1.00 & 2.85 & 0.391 & 0 \\
F1 & 1.23 & 2.85 & 0 & 7 \\
F2 & 1.00 & 1.60 & 0 & 15 \\
F3 & 1.00 & 2.85 & 0 & 0 \\
F4 & 1.00 & 2.85 & 0 & 15 \\
\hline
\end{tabular}

Two piezo-resistive pressure transducers (Endevco model 8510B-1) were connected at the bottom of the pipe at distances of $6.45 \mathrm{~m}$ and $15.70 \mathrm{~m}$ downstream of the center of the upstream standpipe. Outputs from these transducers were sent to a data acquisition system (National Instruments DAQPad MIO-16XE-50) at a frequency of $10 \mathrm{~Hz}$ for a total duration of $130 \mathrm{~s}$, sufficient to capture both the initial filling front as well as the return of the bore to the upstream end of the system.

The pipe system was initially at rest for each experiment and the directional valve was set to the waste position. Once the desired discharge was established, the directional valve was switched to admit flow into the 
pipe system. Once the bore had formed downstream and propagated to the upstream standpipe, the flow was switched back to waste to prevent excessive pressurization of the experimental apparatus. The final steady level in the standpipe was recorded at the end of each $130 \mathrm{~s}$ experiment and used to determine the final hydrostatic pressure at each transducer by adding the difference in elevation (due to slope) between the standpipe and the transducer. This pressure (together with an initial pressure of zero gauge) was used to scale the transducer readings in order to obtain values of pressure throughout the duration of the experiment. Flow rates of $2.36 \mathrm{~L} / \mathrm{s}$, $1.91 \mathrm{~L} / \mathrm{s}, 1.39 \mathrm{~L} / \mathrm{s}$, and $0.84 \mathrm{~L} / \mathrm{s}$ were tested for the single bore experiments to capture a range of both pipe-filling bores and gradual flow regime transitions. At least three repetitions were performed for each of the experimental settings in Tables 15.1 and 15.2 and the measured pressures were quite consistent among the different repetitions.

\subsection{Numerical Model}

In order to demonstrate the ability of a shock capturing numerical model to resolve the flow regime transition, the Two-component Pressure Approach of Vasconcelos et al. (2006) was applied to simulate the flow regime transition experiments; results are presented for one each of the pipe-filling bore and the gradual flow regime transition experiments. Details of the numerical model are documented elsewhere. The numerical procedure basically solves the St. Venant (shallow water) equations for free surface flow. The numerical method uses the Roe first order upwind scheme with special consideration in order for the St. Venant equations to simulate pressurized flows. The normal strategy is to employ the Preissman slot scheme such as implemented by Capart et al. (1997) in which the pipe area is augmented by modeling an imaginary slot at the top of the pipe. When the actual pipe becomes surcharged, water rises in the slot. A desired acoustic wave speed is modeled by selecting the slot width to yield a free surface wave speed equal to the desired acoustic wave speed. The two-component pressure approach takes an alternate approach to accomplish the same objectives. Instead of the slot, the pipe walls are considered to be elastic although the fluid is considered to be incompressible. By proper selection of the wall elasticity, a desired acoustic wave speed can be represented in the model. Vasconcelos (2005) demonstrated that for the assumption of an incompressible flow with elastic pipe walls, there is a termby-term correspondence between the equations for pressurized flow and the St. Venant equations. 
The upstream boundary condition assumed a constant inflow rate into the upstream standpipe. The momentum of the falling water impinging on the pipe elbow was not included in the boundary condition formulation but the filling dynamics of the shaft were included by applying continuity and energy equations between the filling shaft and the first downstream computational node. It is acknowledged that the use of the St. Venant equations assuming hydrostatic pressures is not strictly valid in simulating the initial filling front due to the curvature of the flow at the front of the initial advance in the initially empty pipe. It is not possible to propagate an initial filling front in a dry pipeline and it is therefore necessary to perform the simulation starting from an initial condition that considers a very small uniform flow depth. The exact value of this depth does not have an influence on the predictions so long as the depth is small.

\subsection{Results}

\subsubsection{Flow Regime Transition Experiments}

The experimental flow rates investigated were in the range of peak design discharges expected for the previously mentioned Washington DC tunnel project considering the laboratory setup to be a Froude scaled model of a preliminary proposed design. Numerical simulations had indicated the occurrence of gradual flow regime transitions in all but the most extreme cases analyzed. Figure 15.5 presents the pressure records for one experiment at a discharge that was intermediate in the range tested and for which a gradual flow regime transition was observed. The pressure records are for both measurement locations. One can detect the initial filling front, the bore returning following the reflection at the downstream end of the pipe, and the subsequent increase in pressure until the pressure head exceeds the pipe crown, indicating a pressurized state. It should be noted that the actual filling scenario projected for the project involves a gradual build-up in discharge for nearly three hours before the maximum discharge occurs for the design event which has a $15 \mathrm{y}$ return period on the rainfall. Consequently, the tunnel is not full when the peak discharge occurs. However, if it was assumed that the tunnel was initially half full from a previous rainfall event, then the tunnel was predicted to fill completely at about the time that the peak discharge occurred for key inflow points in the system. However the model did not predict pipe-filling bores, even for that situation primarily due to the fact that the proposed design has side tunnels that provide extra 
storage during the filling process and therefore reduce the effective discharge in the tunnel. Pipe-filling bores were only predicted for extreme events such as the $100 \mathrm{y}$ discharge.

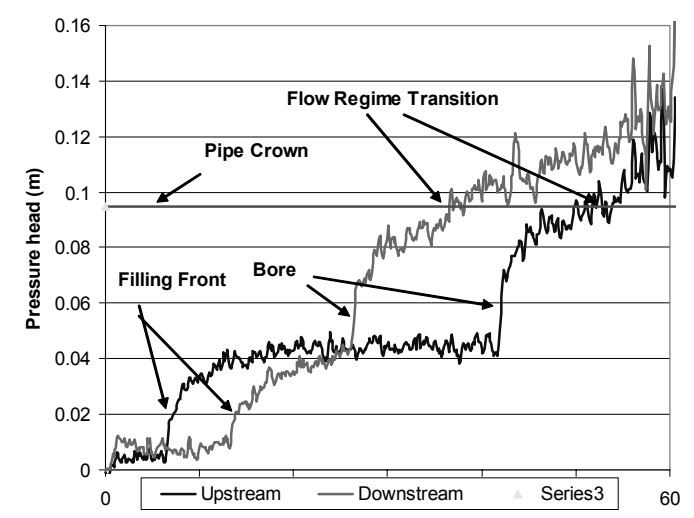

Figure 15.5 Free surface bore with a gradual flow regime transition, $Q=1.39 \mathrm{~L} / \mathrm{s}$.

\section{Pipe-Filling Bore}

Pipe-filling bores were observed for the discharge of $2.4 \mathrm{~L} / \mathrm{s}$ (experiments 1a through 1c) as well as for a discharge of $1.9 \mathrm{~L} / \mathrm{s}$ (experiments 2 a through $2 \mathrm{~d})$. The initial bore formed upon reflection of the filling front at the downstream end was a free surface bore that relatively quickly evolved into a pipe-filling bore. The distance from the downstream capped end to where the pipe filling bore formed was greater for the lower flow rate but still within $2 \mathrm{~m}$ from the downstream end of the pipe and well before the bore reached either of the two pressure transducers. The pressure data for one such experiment (experiment 1b) where a pipe-filling bore formed is shown in Figure 15.6. For this experimental condition, the water level for the initial front was somewhat greater than the centerline of the pipe at the time of bore arrival. This nearly vertical bore creates a surcharge condition behind the bore front; this is the type of bore assumed in most shock fitting numerical models. The pipe-filling bore essentially acts as a "water piston" pushing the air in the pipe out ahead of it and so long as adequate ventilation is provided at the inlet end of the pipeline, the air never becomes pressurized and no significant quantities are trapped as air pockets along the pipeline. 
Figure 15.6 also presents numerical simulation results for these experimental conditions. The timing of the bore and the pressures are quite well reproduced by the numerical model. There is a little problem with the initial timing that may be associated with both the inability of the St. Venant equations to simulate the initial filling front as well as using somewhat simplified boundary conditions to describe the inflow. The simulation for this case indicates that the bore was transitioning from a gradual flow regime transition to a pipe filling bore near the location of the upstream pressure transducer while visual observations indicated the occurrence about $40 \mathrm{~cm}$ further upstream. Both the simulation and experimental results indicate the bore strengthens as it propagates between the two measurement locations.

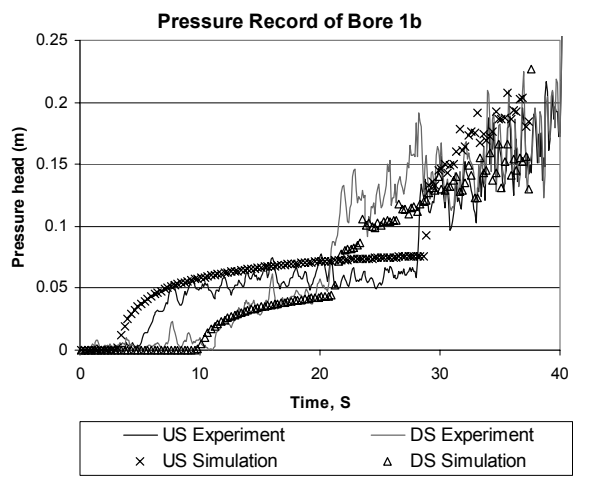

Figure 15.6 Two-Component Pressure Approach simulation results and experimental data for a pipe-filling bore (US = upstream pressure transducer location, $\mathrm{DS}=$ downstream transducer location, $\mathrm{Q}=2.4 \mathrm{~L} / \mathrm{s}$.

\section{Gradual Flow Regime Transition}

At lower flow rates, the free surface bore that formed persisted for the entire length of upstream propagation along the pipeline. Behind the bore, the water depth at a particular location increased gradually until it contacted the pipe crown. Once the bore reaches the upstream end of the pipe, the reflection at that location closes the flow cross-section resulting in the entrapment of air above the portion of the flow not yet pressurized. Video observations for this flow rate showed large air pockets trapped in the pipe, which propagated upstream and eventually slugged up through the inflow standpipe. Previous work by the authors (Wright et al., 2007) has indicated that the phenomenon of geysering may occur in this situation as the air rising through a vertical 
shaft partially filled with water displaces that water in front of it. That portion of the pressure record is not included in Figure 15.5, since the inflow was typically switched off as the bore arrives at the upstream end of the pipeline.

Despite these limitations, there is a good agreement between the experimental data and the numerical simulations for the gradual flow regime transition as indicated in Figure 15.7. The timing of the bore propagation as well as other features of the flow indicates that the numerical scheme is able to accurately resolve the free surface bore. The hydraulic resistance of the pipe was modeled using the Manning equation with a resistance coefficient for smooth pipes and this may result in the under-estimation of the actual resistance (and thus under-estimate the increase of depth following the bore passage) due to the low Reynolds numbers in the experiment. In spite of this, the nature of the gradual flow regime transition is reasonably well described by the numerical simulation. The extreme nature of the flow introduction makes this a quite rigorous test of the numerical model framework.

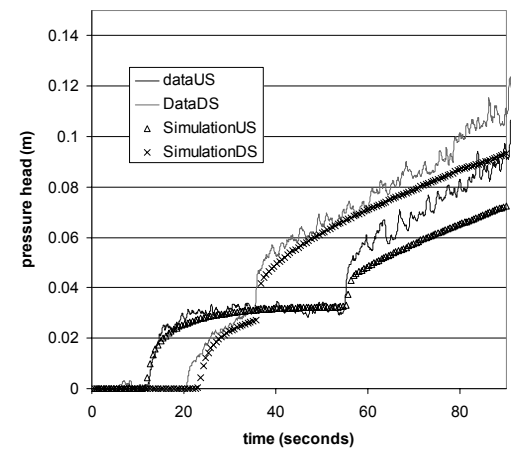

Figure 15.7 Two-Component Pressure Approach simulation results and experimental data of a gradual flow regime transition (US = upstream pressure transducer location, DS = downstream transducer location, $\mathrm{Q}=0.844 \mathrm{~L} / \mathrm{s}$. Run $4 \mathrm{~b}$.

\subsubsection{Bore Collision Experiments}

These experiments were performed as described earlier to create conditions where air was trapped between two approaching bore fronts where geysering might be expected at a vertical riser installed in the region where the air was trapped. The $0.038 \mathrm{~m}$ diameter riser was $2.5 \mathrm{~m}$ tall corresponding to a prototype height of $188 \mathrm{~m}$ if the model pipeline was considered to be representative of the proposed Washington DC tunnel system. In spite of this 
large height, water spilled out the top of the riser in several experiments. What was visually observed was an initial column of water perhaps tenfifteen $\mathrm{cm}$ in height within the riser. As the discrete air pockets approached the riser they began to lift the water up in the riser. Although one air pocket was insufficient to lift the water the entire $2.5 \mathrm{~m}$, another air pocket arrived to push the water still further up the riser until the combined effect was sufficient to lift the water the entire riser height.

A pressure trace of two different experiments is presented in Figure 15.8, one being where the vent riser was removed for the same experimental conditions. The large increase in pressure towards the end of each experiment is associated with the rise of the water at the inflow end of the system as opposed to a pressure increase associated with the collision of the bores or other transient effects within the pipeline. What appears to be a large pressure spike is simply the increase in pressure as the entire pipe goes full, with the pressure dropping off as the inflow was switched off. Regardless, the measured pressure head never approached the $2.5 \mathrm{~m}$ riser height and yet the water spilled out the top of the riser. One can see small pressure spikes (of about ten $\mathrm{cm}$ amplitude) in the record, especially on the rising limb of the pressure trace. These pressure spikes are associated with the release of air pockets from the system.

These results reinforce observations in previous experiments that trapped air in rapidly filling pipelines can be a significant influence on the rise of water in vertical shafts attached to tunnels. It is stressed that because of the small scale of the laboratory experiments, no absolute correlation with large scale geysering events such as displayed in Figure 15.1 is possible, but these observations are strongly suggestive of a link between trapped air and geysers.

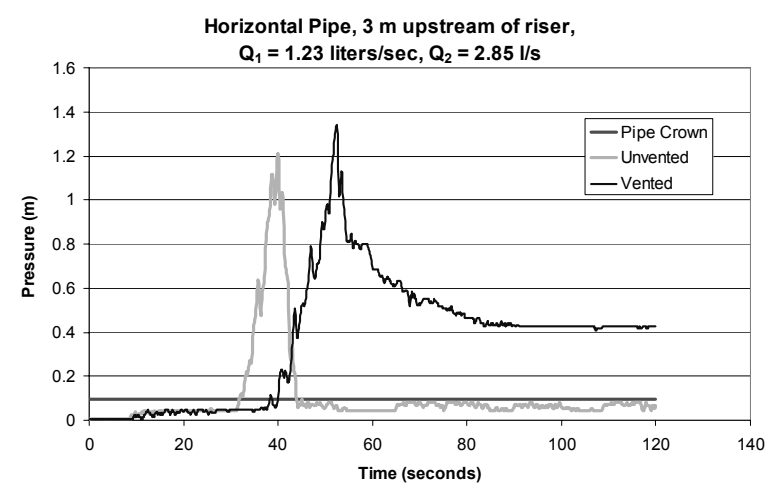

Figure 15.8 Pressure traces for several typical experiments with a $2.5 \mathrm{~m}$ tall riser installed near the center of the pipeline. 


\subsubsection{Geyser Mitigation Experiments}

Given the observations in the previous section, some suggestions are possible for mitigating geyser formation. The impression is that sufficient ventilation to eliminate air pockets without interactions with water in vertical shafts is probably not feasible. The dilemma is that tunnel filling is largely beyond the control of the designer and can be highly variable due to spatial and temporal variations in actual rainfall events. It may be possible to relieve pressures in the trapped air by sufficient ventilation, but without a complete understanding of the geysering process, it seems difficult to make generalizations. Consequently, solutions that allow air pockets to penetrate through the water in the riser without generating the lift are desired. This section describes two approaches that were investigated and the observations from the experimentation.

The first approach modified the vertical riser by placing a short horizontal segment a short distance up from the pipeline connection. The diameter was unchanged however. Figure 15.9 is a schematic of this approach. The concept behind this approach was that a vertically stratified flow would develop in the horizontal segment of the pipe with air on the top, water on the bottom. It was presumed that this section would allow the air to bypass the water. In practice, this configuration significantly reduced the height of the water surge in the riser but was not entirely successful. The problem was the dynamic nature of the air water interaction and the riser diameter was insufficient to prevent water from occupying the entire cross-section of the horizontal segment of pipe. This prevented the free escape of air and created some surging in the riser above the horizontal segment. The configuration was altered so that the horizontal segment was sloped upwards and this was more successful in venting air, but some residual problems existed. An additional consideration is that since most storage tunnels are constructed well below grade, there are constructability issues with such a configuration.

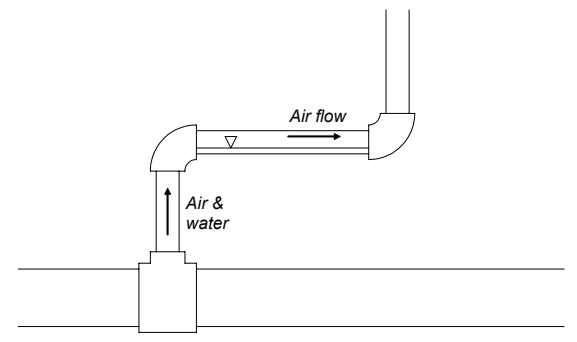

Figure 15.9 Mitigation of geysers by addition of a horizontal section to vertical riser. 
A second mitigation approach involved a riser consisting of a small diameter segment near the bottom connected to a larger diameter shaft a short distance above the pipe connection; Figure 15.10 is a schematic of this configuration. The concept behind this approach is that the air bubble rising in the small diameter shaft would be able to push through the water in the larger diameter segment without significant upward displacement of that water. This approach was found to work well in preventing surging with only small water level fluctuations within the large diameter segment of the riser as the several air pockets were expelled. Violent accelerations were still observed in the small diameter pipe, but were mostly dissipated at the expansion. Although this concept probably should be explored further to optimize design aspects, that step was not taken due to the uncertainty in scale effects in the small scale experiments. Nevertheless, it appears to be an effective solution for geyser prevention.

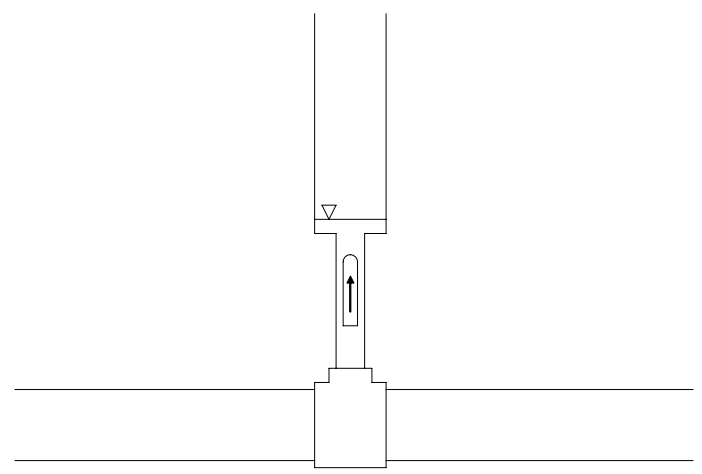

Figure 15.10 Mitigation of geysers by addition of a larger diameter section to vertical riser.

\subsection{Conclusions}

Understanding the potential for a system to experience either large pipe surges or geysering is important in the design of stormwater or combined sewer overflow systems. This work demonstrates that there is not a distinct bore type that will develop in the conduit under all conditions, and the flow regime transition may occur along with the passage of the bore or through the gradual increase in depth behind a free surface bore. The type of bore 
expected is a function of the inflow hydrograph but will also depend on a number of other factors including system geometry. Several conclusions may be drawn as a result of this work:

Although many numerical models treat propagating bores in closed conduits as pipe-filling bores, this is not necessarily the typical condition for a system, and free surface bores with long distances to the actual flow regime transition may exist within the system.

Existing shock-fitting numerical methods will only accurately predict the behavior of bores in systems where free surface bores are unlikely to occur. Since this situation occurs under high flow rates, it is expected that a real system will also (and more often) experience the lower flow rates where free surface bores will develop, and therefore, alternative numerical techniques are required in order to predict the range of bore behavior.

Shock-capturing methods that can accurately predict bore characteristics for both free surface and pipe filling bores have significant utility in analyzing the extreme conditions that will control design of stormwater systems. The two-component pressure approach proposed by Vasconcelos, et al. (2006) is an attractive method for this purpose.

The gradual flow regime transition following a free surface bore is more conducive to air entrapment within a system compared to the pipe-filling bore state. Air is especially likely to be entrapped when a free surface bore with a gradual flow regime transition is reflected off a conduit transition and the reflection fills the pipeline. The large volumes of trapped air may lead to geysering in some systems where sufficient ventilation is not provided.

Evidence is presented demonstrating that water can be lifted large distances in ventilation shafts by the release of air pockets trapped within the shaft. The combined effects of multiple pockets may accentuate the geysering potential. These large vertical lifts of water are not necessarily accompanied by large system pressures. It was found that geometrical changes to the ventilation shaft could greatly reduce the height to which water will rise in the shaft. In particular, a configuration of a small diameter shaft at the bottom connected to a larger diameter shaft was quite effective in minimizing water rise within the shaft.

\section{Acknowledgments}

The authors would like to acknowledge the support of the CNPq, National Council of Scientific Development - Brazil, and FINATEC Agency which have provided financial support for the second author. 


\section{References}

Capart, H., Sillen, X., and Zech, Y. 1997. Numerical and Experimental Water Transients in Sewer Pipes. J. Hydr. Res. 35 (5), 659-670.

Cardle, J.A. and Song, C.S.S. 1988. Mathematical Modeling of Unsteady Flow in Storm Sewers. Int. J. Eng. Fluid Mechanics, 1(4), 495-518.

Guedes de Carvalho, J.R.F., Talaia, M.A.R. and Ferreira, M.J.F. 2000. Flooding Instability of High-Density Gas Slugs Rising in Vertical Tubes Filled with Water.

Guo, Q. 1989. Geysering in Urban Storm Drainage Systems. Proc. XXIII IAHR Cong. Ottawa, Canada S75-S81.

Guo, Q., and Song, C.S.S. 1990. Surging in Urban Storm Drainage Systems. J. Hydraulic Engineering, V. 116(12), 1523-1537.

Politano, M., Odgaard, A.J., and Klecan, W. 2007. Case Study: Numerical Evaluation of Hydraulic Transients in a Combined Sewer Overflow Tunnel System. J. Hyd. Eng. 133 (10) 1103-1110.

Trajkovic, B., Ivetic, M., Calomino, F., and Dippolito, A. 1999. Investigation of Transition from Free Surface to Pressurized Flow in a Circular Pipe. Water Sci. Technol., 39(9), 105-112.

Vasconcelos, J.G. 2005. Dynamic Approach to the Description of Flow Regime Transition in Stormwater Systems. PhD dissertation, Environmental Engineering, The University of Michigan, Ann Arbor, Michigan.

Vasconcelos J.G. and Wright, S.J. 2006. Mechanisms for Air Pocket Entrapment in Stormwater Storage Yunnels. Proceedings of World Water and Environmental Resources Congress, Omaha, Nebraska, Paper 40856-14275.

Vasconcelos, J.G., Wright, S.J. and Roe, P.L. 2006. Improved Simulation of Flow Regime Transition in Sewers: Two-component pressure approach. J. Hydraulic Engineering, 132(6), 553-562.

Wright, S.J., J. Lewis and J. Vasconcelos. 2007. "Mechanisms for Stormwater Surges in Vertical Shafts." Journal of Water Management Modeling R227-05. doi: 10.14796/JWMM.R227-05

Zhou, F, Hicks, F. E., and Steffler, P. M. 2002. Transient flow in a rapidly filling horizontal pipe containing trapped air. J. Hydr. Engrg., 128(6), 625-634. 